\title{
Association between dietary calcium and phosphorus intakes, dietary calcium/phosphorus ratio and bone mass in the Korean population
}

\author{
Kyung-Jin Lee ${ }^{1}$, Kyung-Soo Kim², Ha-Na Kim', Jin-A Seo ${ }^{1}$ and Sang-Wook Song ${ }^{1 *}$
}

\begin{abstract}
Background: Osteoporosis has become a major public health issue. Among various factors affected bone health, not only dietary calcium and phosphorus intakes, but also the dietary calcium/phosphorus ratio could relate to bone health. Therefore, we evaluated whether dietary calcium and phosphorus intakes, and dietary calcium/phosphorus ratio are associated with bone mass in Korean adults $\geq 20$ years of age.

Methods: The analysis used data from the Korean National Health and Nutrition Examination Survey, a cross-sectional survey of Korean civilians, conducted from January to December 2010. A total of 4,935 participants (2,309 men and 2,626 women) were analyzed in this study. Dietary calcium and phosphorus intakes of the participants were estimated using 24-h dietary recall. Bone mass densities for the whole body, femoral neck, and lumbar spine were measured by dual-energy X-ray absorptiometry.

Results: Dietary calcium intake and dietary calcium/phosphorus ratio were positively related to bone mass density for femoral neck in men $\geq 50$ years of age ( $p=0.046$ and 0.041 , respectively). Dietary calcium intake showed positive associations with bone mass density for whole body in premenopausal women $(p=0.022)$.

Conclusions: Increased calcium intake and high dietary calcium/phosphorus ratio might have favorable effects on bone mass in Korean adults. Additional gender- and age-specific studies are needed to further identify the influence of calcium and phosphorus intakes, and the dietary calcium/phosphorus ratio on bone mass.
\end{abstract}

Keywords: Calcium, Phosphorus, Calcium/phosphorus ratio, Bone mineral density, Korean adults

\section{Background}

Osteoporosis is a skeletal condition characterized by low bone mass and architectural deterioration of bone tissue [1]. Osteoporosis has become one of the public health issues because it is associated with an increased risk of osteoporotic fractures and mortality that contribute to a large socio-economic burden [2-4]. Furthermore, the rates of osteoporosis and osteoporotic fractures are high and have been rapidly increasing worldwide. In the United States in 2010, the prevalence of osteoporosis and low bone mass in adults older than 50 years of age

\footnotetext{
* Correspondence: sswkoj@unitel.co.kr

'Department of Family Medicine, St. Vincent's Hospital, College of Medicine, The Catholic University of Korea, 93 Jungbudaero, Paldal-gu, Suwon, Gyeonggi-do 442-723, Republic of Korea

Full list of author information is available at the end of the article
}

was $10.3 \%$ and $43.9 \%$ [5]. In addition, the number of osteoporotic fractures exceeds 1.5 million per year, and it has been projected that hip fractures will increase from an estimated 1.7 million in 1990 to 6.3 million in 2050 [6]. The number of hip fractures in the Asia-Pacific area is expected to increase continuously, and is projected to reach 3.25 million by 2050 [7]. In Korea in 2009, the prevalence of osteoporosis in adults older than 50 years of age was $23.1 \%$, and the prevalence in men and women was $8.1 \%$ and $38.7 \%$, respectively [8].

Although osteoporosis has been focused primarily on postmenopausal women, osteoporosis in men has become a public health concern. Age-specific incidence rate of hip fracture in men was about half compared with that in women, but the mortality in men with hip fracture was fourfold higher than that in women [9]. Additionally, it is important not to overlook low bone mass in premenopausal 
women since the occurrences of osteoporosis in the future might be associated with the insufficient acquirement of peak bone mass at a young age [10].

There are numerous factors that influence on bone mass, such as age, body weight, physical activity, cigarette smoking, excessive alcohol intake or concomitant diseases [11]. Among them, the nutrients are also one of the associated components in the achievement of peak bone mass and the control of bone loss. Previous studies have been shown that various nutrients such as vitamin A and its precursors [12,13], ascorbic acid [13], vitamin $\mathrm{K}[14,15]$, sodium [16], magnesium $[17,18]$, calcium and vitamin D [19,20], and phosphorus [21,22], as well as various foods [23-26] are related to bone mass.

Hydroxylapatite, which is one of the primary mineral compounds in osseous tissue is composed of calcium and phosphate; thus, adequate intake of calcium and phosphorus might be important for bone health [27]. A number of studies have investigated the association between dietary calcium and phosphorus intakes and bone mass $[28,29]$. In addition, there were several studies that high dietary calcium/phosphorus ratio might have a positive influence on bone mass [28,30]. However, to date, no studies in Korean population have focused on the correlation between bone mass and not only dietary calcium and phosphorus intakes but also dietary calcium/ phosphorus ratio. Therefore, we evaluated whether dietary calcium and phosphorus intakes and dietary calcium/ phosphorus ratio are associated with bone mass in Korean adults classified as men younger or older than 50 years of age and pre- or postmenopausal women using data from the Korean National Health and Nutrition Examination Survey (KNHANES) V-1.

\section{Methods}

\section{Study population}

The present study utilized data collected from the KNHANES V-1, which was conducted between January 2010 and December 2010. The KNHANES assessments are implemented by the Korea Centers for Disease Control and Prevention (KCDC) at 3-year intervals to evaluate the status of public health and to provide baseline data for the development, establishment, and assessment of public health policies in the Korean population. The KNHANES data are obtained from participants who are non-institutionalized, older than 1 year of age, and who were selected using a stratified multi-stage cluster probability sampling design to ensure an independent, homogeneous, and nationally representative sampling. The data consist of household interviews, anthropometric and biochemical measurements, and nutritional status assessments. All protocols were approved by the Institutional Review Board of the KCDC, and the participants provided written informed consent at baseline.
The KNHANES V-1 recruited 10,938 participants, and 8,958 fully completed the survey (participation rate: $81.9 \%$ ). Of these 8,958 participants, the present cross-sectional study initially examined data of 6,939 adults who were 20 years of age or older regarding bone mass measured by dual-energy X-ray absorptiometry (DXA). Participants missing information or values for major variables $(n=902)$, with abnormal daily energy intake $(<500 \mathrm{kcal}$ or $>5000 \mathrm{kcal}$; $\mathrm{n}=87)$, taking hormone replacement therapy $(\mathrm{n}=338)$, with a past history of spine, hip, or wrist fractures $(n=228)$, taking medicine for osteoporosis $(\mathrm{n}=32)$, and with known renal failure $(n=7)$, liver cirrhosis $(n=16)$, thyroid disease $(n=203)$, rheumatoid arthritis $(n=114)$, or cancer $(n=77)$ were excluded. Thus, the final sample of the present study included 4,935 participants. The present study was approved by the Institutional Review Board of the Catholic University of Korea (IRB approval number: VC14EIME0161).

\section{Dietary assessments}

Trained interviewers estimated dietary calcium and phosphorus intakes of the participants using 24-h dietary recall (milligrams per day). Additionally, tools such as food models, two-dimensional food volumes, and containers were also used to assist participants' recall regarding nutrient intake. A qualitative food frequency questionnaire for 63 common food items that comprised 10 frequency responses was used to obtain additional dietary information.

\section{Bone mass measurements}

Bone mass density (BMD, $\mathrm{g} / \mathrm{cm}^{2}$ ) for the whole body, femoral neck, and lumbar spine (1-4) were measured by DXA (DISCOVERY-W fan-beam densitometer, Hologic, Inc., Waltham, Mass., USA). All BMD measurements were performed according to a standardized protocol and guidelines based on the International Society for Clinical Densitometry official positions [31].

\section{Laboratory measurements}

Blood samples were collected from the antecubital vein of each participant after at least $12 \mathrm{~h}$ of fasting. The samples were processed, immediately refrigerated, transported in cold storage to the Central Testing Institute in Seoul, Korea, and analyzed within $24 \mathrm{~h}$ of arrival at the testing facility. Serum ferritin level was measured by immunoradiometric assay using a $\gamma$-counter (1470 Wizard, PerkinElmer, Turku, Finland), and serum alkaline phosphatase was measured using an auto-analyzer (Hitachi Automatic Analyzer 7600, Hitachi, Japan). Serum total 25-hydroxyvitamin D concentrations were measured by radioimmunoassay methods using a $\gamma$-counter $(1470$ Wizard, PerkinElmer, Turku, Finland), and the standard deviation index was 0.50 or less during three times assessment in Vitamin D External Quality Assessment Scheme. 
The coefficients of variation for intra- and inter-assay were $2.9-5.5$ and $6.3-12.9 \%$ respectively and the limits of detection were $1.5 \mathrm{ng} / \mathrm{mL}$.

\section{Clinical and anthropometric measurements}

The anthropometric measurements of the participants were conducted by specially trained examiners. Height and weight were measured following an overnight fast while the participants wore a lightweight gown, waist circumference was assessed using a measuring tape in the horizontal plane around the umbilical region after exhaling, and body mass index (BMI) was calculated as a participant's weight (in kilograms) divided by the square of their height (in meters).

Self-reported information regarding age, gender, smoking, alcohol consumption, residential area, household income, education level, the amount of physical activity, and the presence of dietary supplements and in women, total duration of breast feeding were obtained. Cigarette smoking was classified into three groups based on current use estimates: non-smoker, ex-smoker, and current smoker. Alcohol consumption was classified into three groups: abstinence (no alcoholic drinks consumed within the last year), moderate drinking (less than 14 standard drinks consumed per week for men or seven for women), and heavy drinking (more than 14 standard drinks consumed per week for men or seven for women). Residential area was classified as either urban or rural. Household income was classified using monthly equivalised household income (quartiles), which was estimated as the total monthly household income divided by the square root of the total number of household members. Education level was classified as the period of education ( $<10$ years and $\geq 10$ years). Physical activity was classified as the metabolic equivalent of task minutes per week (MET-minutes per week) and was calculated using the scoring protocol of the Korean version of the International Physical Activity Questionnaire short form: low ( $<600$ MET-minutes per week), moderate ( $\geq 600$ to $<3,000$ MET-minutes per week), or high $(\geq 3,000$ MET-minutes per week). Participants taking any dietary supplementation for 2 weeks or more during the previous 1 year were defined as ones taking 'dietary supplement'.

\section{Statistical analysis}

To analyze the data, which were obtained using a complex sampling design, the SAS PROC SURVEY module which considers strata, clusters, and weights was utilized. All analyses were performed using sample weights from the KNHANES V-1. The gender-specific characteristics of the study population were analyzed using independent $\mathrm{t}$-tests for continuous variables and Chi-squared tests for dichotomous variables, and all values were expressed as means \pm standard errors, percentages, or as geometric means and $95 \%$ confidence intervals for skewed distributions. Variables with skewed distributions were analyzed after a logarithmic transformation (log-transformation) was performed. The correlations among dietary calcium, dietary phosphorus, the calcium/ phosphorus ratio and BMD were analyzed using a Pearson's correlation analysis and the associations among dietary calcium, dietary phosphorus, and the calcium/phosphorus ratio and BMD were analyzed using a multiple regression analysis. Model 1 was adjusted for age, income, education, residential area, alcohol, smoking, physical activity, energy intake per day, the presence of dietary supplements, and total duration of breast-feeding in women. Model 2 was adjusted for age, income, education, residential area, alcohol, smoking, physical activity, energy intake per day, the presence of dietary supplements, total duration of breast-feeding in women, and BMI. Model 3 was adjusted for age, income, education, residential area, alcohol, smoking, physical activity, energy intake per day, the presence of dietary supplements, total duration of breast-feeding in women, BMI, and alkaline phosphatase, ferritin, and vitamin D levels. All statistical analyses were conducted using the SAS software (ver. 9.2, SAS Institute; Cary, NC, USA), and $\mathrm{p}$ values $<0.05$ were considered to indicate statistical significance.

\section{Results}

This study was conducted using a total of 4,935 participants (2,309 men and 2,626 women). The mean daily intake of dietary calcium was $588.0 \mathrm{mg}$ for men younger than 50 years of age and $589.8 \mathrm{mg}$ for men 50 years of age or older ( $\mathrm{p}=0.918), 481.1 \mathrm{mg}$ for premenopausal women and $434.0 \mathrm{mg}$ for postmenopausal women $(\mathrm{p}<0.001)$. The mean daily intake of dietary phosphorus was $1435.3 \mathrm{mg}$ for men younger than 50 years of age and $1337.5 \mathrm{mg}$ for men 50 years of age or older $(\mathrm{p}<0.001), 1079.8 \mathrm{mg}$ for premenopausal women and $968.6 \mathrm{mg}$ for postmenopausal women ( $\mathrm{p}<0.001$ ). The daily calcium/phosphorus ratio was 0.38 for men younger than 50 years of age and 0.40 for men 50 years of age or older $(p=0.005), 0.41$ for premenopausal women and 0.39 for postmenopausal women $(\mathrm{p}=0.017)$ (Table 1).

The correlation coefficients for dietary calcium and phosphorus intake, and dietary calcium/phosphorus ratio with bone mass are shown in Table 2. Significant positive correlations were observed between dietary calcium intake and dietary calcium/phosphorus ratio and BMD for all measured regions, and dietary phosphorus intake and BMD for whole body and femoral neck regions in men 50 years of age and older. In men younger than 50 years of age, dietary calcium and dietary calcium/phosphorus ratio were related to lumbar spine BMD positively and to whole body BMD negatively. In postmenopausal women, 
Table 1 Clinical and laboratory characteristics of the study participants

\begin{tabular}{|c|c|c|c|c|c|c|}
\hline & & Men & & & Women & \\
\hline & $\begin{array}{l}<50 \text { years } \\
(n=1,405)\end{array}$ & $\begin{array}{c}\geq 50 \text { years } \\
(n=904)\end{array}$ & $p$ value & $\begin{array}{c}\text { Postmenopausal } \\
(n=1,758)\end{array}$ & $\begin{array}{l}\text { Premenopausal } \\
(n=868)\end{array}$ & $p$ value \\
\hline Age (years) & $30.4 \pm 0.3$ & $61.3+0.4$ & $<0.001$ & $30.5 \pm 0.3$ & $62.9 \pm 0.5$ & $<0.001$ \\
\hline Current smoker (\%) & 45.8 & 33.1 & $<0.001$ & 4.6 & 5.3 & 0.663 \\
\hline Heavy drinker (\%) & 22.2 & 33.0 & $<0.001$ & 5.4 & 2.2 & 0.001 \\
\hline Residential area (Urban,\%) & 82.3 & 67.3 & $<0.001$ & 83.0 & 63.9 & $<0.001$ \\
\hline Household income (Q1,\%) & 12.4 & 23.2 & $<0.001$ & 10.8 & 33.7 & $<0.001$ \\
\hline Education level ( $\geq 10$ years, $\%$ ) & 75.7 & 47.2 & $<0.001$ & 73.2 & 19.7 & $<0.001$ \\
\hline Physical activity (\%) & & & 0.483 & & & 0.042 \\
\hline Low & 29.6 & 29.9 & & 39.2 & 37.9 & \\
\hline Moderate & 41.2 & 38.4 & & 43.0 & 38.5 & \\
\hline High & 29.2 & 31.7 & & 17.8 & 23.6 & \\
\hline Dietary supplement (yes,\%) & 74.7 & 70.2 & 0.06 & 68.7 & 61.6 & 0.007 \\
\hline Height (cm) & $170.7 \pm 0.3$ & $167.2 \pm 0.2$ & $<0.001$ & $159.1 \pm 0.2$ & $152.7 \pm 0.3$ & $<0.001$ \\
\hline Weight (kg) & $68.8 \pm 0.4$ & $66.3 \pm 0.4$ & $<0.001$ & $55.8 \pm 0.3$ & $56.8 \pm 0.3$ & 0.021 \\
\hline Body mass index $\left(\mathrm{kg} / \mathrm{m}^{2}\right)$ & $23.5 \pm 0.1$ & $23.7 \pm 0.1$ & 0.264 & $22.0 \pm 0.1$ & $24.3 \pm 0.1$ & $<0.001$ \\
\hline Waist circumference $(\mathrm{cm})$ & $80.6 \pm 0.3$ & $85.2 \pm 0.4$ & $<0.001$ & $73.0 \pm 0.4$ & $82.6 \pm 0.3$ & $<0.001$ \\
\hline Alkaline phosphatase $(\mathrm{IU} / \mathrm{L})^{*}$ & $268.9(260.0-278.1)$ & $231.6(226.5-236.9)$ & $<0.001$ & $207.0(202.1-212.0)$ & $250.4(245.3-255.6)$ & $<0.001$ \\
\hline Ferritin $(\mathrm{ng} / \mathrm{mL})^{*}$ & 81.8(77.8-85.9) & $92.5(85.8-99.7)$ & 0.007 & $22.2(21.0-23.4)$ & $55.2(51.2-59.5)$ & $<0.001$ \\
\hline Serum 25(OH)D (ng/mL) & $17.7 \pm 0.3$ & $20.9 \pm 0.4$ & $<0.001$ & $15.8 \pm 0.3$ & $18.3 \pm 0.4$ & $<0.001$ \\
\hline Calcium intake (mg/day) & $588.0 \pm 11.6$ & $589.8 \pm 14.1$ & 0.918 & $481.1 \pm 8.7$ & $434.0 \pm 11.7$ & $<0.001$ \\
\hline Phosphorus intake (mg/day) & $1435.3 \pm 20.0$ & $1337.5 \pm 19.9$ & $<0.001$ & $1079.8 \pm 12.9$ & $968.6 \pm 20.1$ & $<0.001$ \\
\hline Calcium/phosphorus ratio ${ }^{*}$ & $0.38(0.37-0.39)$ & $0.40(0.39-0.41)$ & 0.005 & $0.41(0.40-0.42)$ & $0.39(0.37-0.41)$ & 0.017 \\
\hline Bone mass density $\left(\mathrm{g} / \mathrm{cm}^{2}\right)$ & & & & & & \\
\hline Whole body & $1.16 \pm 0.01$ & $1.16 \pm 0.01$ & 0.861 & $1.10 \pm 0.01$ & $1.00 \pm 0.01$ & $<0.001$ \\
\hline Lumbar & $0.94 \pm 0.01$ & $0.96 \pm 0.01$ & 0.196 & $0.95 \pm 0.01$ & $0.81 \pm 0.01$ & $<0.001$ \\
\hline Femoral neck & $0.85 \pm 0.01$ & $0.76 \pm 0.01$ & $<0.001$ & $0.76 \pm 0.01$ & $0.63 \pm 0.01$ & $<0.001$ \\
\hline
\end{tabular}

Values are expressed as means \pm standard errors or percentages and as geometric means ( $95 \%$ confidence intervals) for skewed distributions*. Variables with skewed distributions performed log-transformation. Q1 Quartile 1(the lowest household income), 25(OH)D 25-hydroxyvitamin D.

there were positive relationships between dietary calcium and phosphorus intakes, dietary calcium/phosphorus ratio, and BMD for lumbar spine and femoral neck and in premenopausal women, dietary calcium/phosphorus ratio showed a positive association with femoral neck BMD.

The multivariate-adjusted associations between dietary calcium and phosphorus intakes, calcium/phosphorus intake ratio and BMD are shown in Tables 3 and 4. After adjusting for confounding factors such as age, income, education, residential area, alcohol, smoking, physical activity, energy intake per day, the presence of dietary supplements, total duration of breast-feeding in women, BMI, serum alkaline phosphatase, ferritin, and vitamin D levels, dietary calcium intake and dietary calcium/ phosphorus ratio were positively related to BMD in the femoral neck of men older than 50 years of age and in premenopausal women, dietary calcium intake showed positive associations with the whole body BMD.

\section{Discussion}

The goal of this study was to evaluate the relationships between dietary calcium, phosphorus, calcium/ phosphorus intake ratio, and bone mass in Korean adults. There were positive relationships between dietary calcium intake, calcium/phosphorus intake ratio and femoral neck BMD in men older than 50 years, and dietary calcium intake showed positive associations with BMD for whole body in premenopausal women.

The association between dietary calcium and phosphorus intake, and bone health has been addressed by a number of experimental and epidemiological studies. In a cross-sectional study conducted in Chinese freshmen, adequate calcium intake was a negative association with the risk of osteopenia/osteoporosis [32]. In experimental studies in rats, BMD in a group fed a high-phosphate diet decreased significantly than that in the control group $[33,34]$. In a randomized controlled trial conducted on 
Table 2 Correlations between dietary calcium, phosphorus, calcium/phosphorus ratio and bone mass density

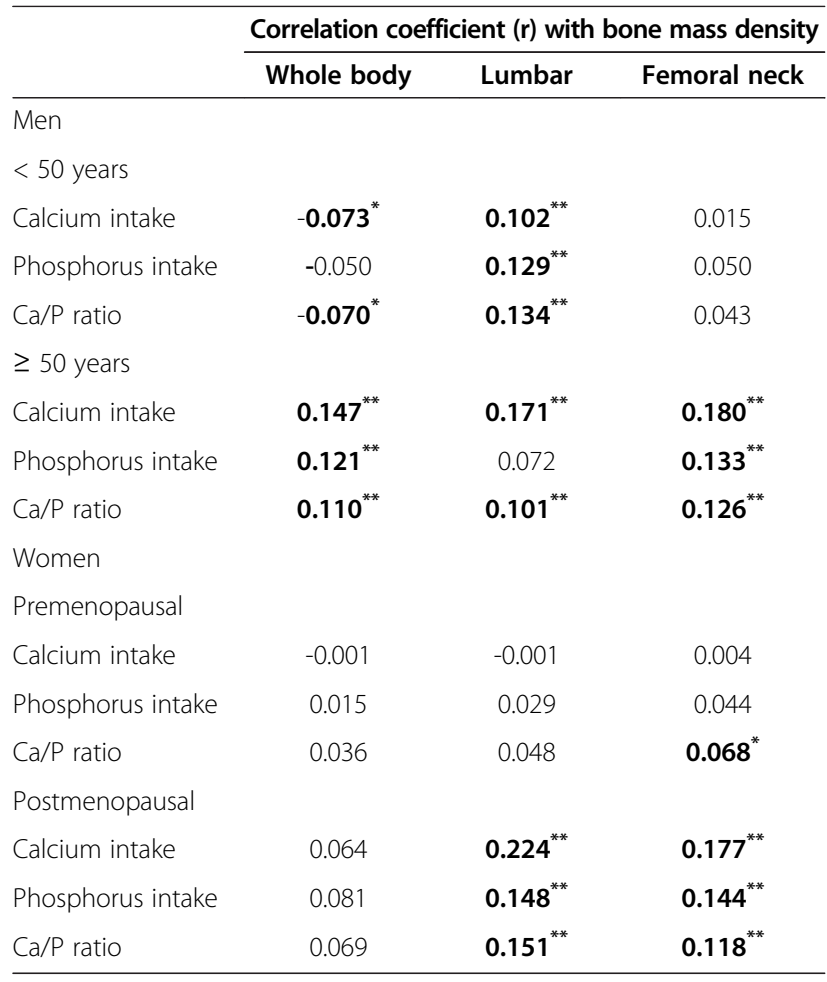

${ }^{*} \mathrm{p}<0.05,{ }^{* *} \mathrm{p}<0.01$. Ca/P ratio Calcium/phosphorus intake ratio. Results in bold indicate statistical significance at the 0.05 level.

healthy women, high phosphorous intake adversely influenced bone metabolism by increasing bone resorption and decreasing bone formation [35]. Along the same lines as other studies on calcium intake and bone mass, as the results of the multivariate-adjusted analysis in this study, dietary calcium intake was positively related to BMD for the femoral neck of men 50 years of age and older, and for the whole body of premenopausal women. However, dietary phosphorous intake showed no association with bone mass in all groups of this study.

Dietary phosphorus is contained in not only protein-rich foods such as meat, dairy products, poultry and fish, but also processed foods that contain phosphate-based additives [36]. In fact, phosphorus is a material for bone formation [27], but excessive phosphorus intakes elevate serum phosphorus levels and disturb the hormonal regulation of calcium and phosphorus, which may result in decreased bone strength and an increased risk of fractures [37], and the deleterious effects of excessive phosphorus intake on bone increase when calcium intake is low [38]. Therefore, adequate dietary calcium intake is needed to overcome the harmful effects of a high phosphorus intake on bone health [39]. In Korea, calcium intake is lower than the dietary reference intakes for Korean [8], and calcium intake in much of the developing countries including Korea is lower than that in the developed countries $[8,40]$. In addition to the low contents of calcium in the Korean diet, many dietary factors unique to traditional Korean foods can also influence the efficiency of calcium absorption. The traditional Korean diet containing high intake of rice, kimchi, and vegetables is composed of low lipids and proteins, and high carbohydrates, and is high in substances such as oxalate, phytate, and fiber that could hamper the absorption of calcium. Additionally, in western countries, excess intake of phosphorus has been an issue on bone health $[21,41,42]$, but in Korea, there have been few concerns on high intake of phosphorus, especially the intakes from food additives. Furthermore, in many countries including Korea, dietary phosphorus intake is higher than recommended levels [41] whereas dietary calcium intake is lower than the nutritional recommendations $[43,44]$, therefore dietary calcium/phosphorus ratio is low [45,46]. In this study, dietary calcium/phosphorus ratio was positively related to BMD for the femoral neck in men 50 years of age and older. The low dietary calcium/phosphorus ratio might alter the homoeostasis of calcium metabolism and be associated with increased serum parathyroid hormone concentration, which may cause increased bone resorption $[47,48]$, suggesting that high calcium/phosphorus intake ratio might be needed to the optimal bone health.

In a cross-sectional study for determining the predictors of bones mass in healthy older men, body composition factors, such as body weight or lean mass were the main factors of bone mass prediction [49], and in another cross-sectional study conducted in adult men, when calcium intake is adequate, protein intake, lean body mass as well as phosphorus intake were beneficial for maintaining bone mass [50]. Thus, some factors including protein intake, body weight or lean mass could influence on the association between phosphorus intake and bone mass. In this study, positive correlations were observed between dietary phosphorus intake and BMD for femoral neck and whole body in men older than 50 years and older and for lumbar spine in men younger than 50 years, but after adjusting for covariates including daily energy intake, BMI, and serum vitamin D levels, the correlations disappeared. Therefore, when evaluating the associations between dietary phosphorus intake and bone mass, the covariates that have effects on the relationship of phosphorus intake and bone mass should be carefully considered.

A number of studies investigating dietary calcium, phosphorus, calcium/phosphorus intake ratio, and osteoporosis have been conducted in women. Ito et al. [28] reported that dietary calcium intake and dietary calcium/phosphorus ratio were positively associated with the bone mass in radius of women aged 18-22 years, and Brot et al. [30] found that dietary calcium/phosphorus ratio was positively related to whole-body mineral content 
Table 3 Multivariate-adjusted associations between dietary calcium, phosphorus, calcium/phosphorus ratio and bone mass density among men

\begin{tabular}{|c|c|c|c|c|c|c|c|c|c|c|c|c|}
\hline & \multicolumn{6}{|c|}{$<50$ years } & \multicolumn{6}{|c|}{$\geq \mathbf{5 0}$ years } \\
\hline & \multicolumn{2}{|c|}{ Whole body } & \multicolumn{2}{|c|}{ Lumbar } & \multicolumn{2}{|c|}{ Femoral neck } & \multicolumn{2}{|c|}{ Whole body } & \multicolumn{2}{|c|}{ Lumbar } & \multicolumn{2}{|c|}{ Femoral neck } \\
\hline & B & $p$ & B & $p$ & B & $p$ & B & $p$ & ß & $p$ & ß & $p$ \\
\hline \multicolumn{13}{|l|}{ Model 1} \\
\hline Calcium intake & 0.000005 & 0.648 & 0.000009 & 0.546 & 0.000007 & 0.552 & 0.000034 & 0.005 & 0.000050 & 0.014 & 0.000039 & 0.002 \\
\hline Phosphorus intake & 0.000012 & 0.109 & 0.000015 & 0.092 & 0.000011 & 0.197 & 0.000014 & 0.118 & 0.000012 & 0.333 & 0.000015 & 0.075 \\
\hline $\mathrm{Ca} / \mathrm{P}$ ratio & -0.018726 & 0.105 & -0.008208 & 0.499 & -0.014333 & 0.327 & 0.026552 & 0.019 & 0.039903 & 0.016 & 0.033198 & 0.001 \\
\hline \multicolumn{13}{|l|}{ Model 2} \\
\hline Calcium intake & 0.000001 & 0.888 & 0.000004 & 0.764 & 0.000002 & 0.823 & 0.000026 & 0.021 & 0.000034 & 0.192 & 0.000029 & 0.014 \\
\hline Phosphorus intake & 0.000012 & 0.099 & 0.000015 & 0.080 & 0.000011 & 0.162 & 0.000013 & 0.212 & 0.000006 & 0.629 & 0.000011 & 0.174 \\
\hline $\mathrm{Ca} / \mathrm{P}$ ratio & -0.022948 & 0.045 & -0.013631 & 0.265 & -0.020154 & 0.160 & 0.020238 & 0.069 & 0.027653 & 0.110 & 0.025128 & 0.013 \\
\hline \multicolumn{13}{|l|}{ Model 3} \\
\hline Calcium intake & 0.000002 & 0.804 & 0.000006 & 0.650 & 0.000003 & 0.741 & 0.000022 & 0.065 & 0.000026 & 0.191 & 0.000023 & 0.046 \\
\hline Phosphorus intake & 0.000013 & 0.089 & 0.000016 & 0.073 & 0.000014 & 0.086 & 0.000008 & 0.359 & 0.000001 & 0.937 & 0.000009 & 0.300 \\
\hline $\mathrm{Ca} / \mathrm{P}$ ratio & -0.020239 & 0.094 & -0.012013 & 0.335 & -0.018413 & 0.216 & 0.017843 & 0.125 & 0.023537 & 0.179 & 0.020974 & 0.041 \\
\hline
\end{tabular}

Model 1: adjustment for age, household income, education level, residential areas, alcohol consumption, smoking, physical activity, energy intake per day, and dietary supplement. Model 2: adjustment for model $1+$ body mass index. Model 3: adjustment for model $2+$ alkaline phosphatase, ferritin, and 25 -hydroxyvitamin $D$. $\mathrm{Ca} / \mathrm{P}$ ratio Calcium/phosphorus intake ratio. Results in bold indicate statistical significance at the 0.05 level.

and bone mass in the spine and femoral neck in women aged 45-58 years. However, in the present study, there were only positive associations between dietary calcium intake and whole body BMD in premenopausal women. The results may be due to other factors affected bone mass, such as thyroid hormone or estrogen [51,52]. However, the possible factors were not considered in the present study because the factors were not measured in the KNHANES, therefore, additional studies adjusting such covariates are warranted to clarify the associations between dietary calcium and phosphorus intakes, calcium/phosphorus intake ratio and bone mass in Korean women.

The present study has several limitations. First, this study was conducted using a cross-sectional design. Second, data about the dietary calcium and phosphorus intake were

Table 4 Multivariate-adjusted associations between dietary calcium, phosphorus, calcium/phosphorus ratio and bone mass density among women

\begin{tabular}{|c|c|c|c|c|c|c|c|c|c|c|c|c|}
\hline & \multicolumn{6}{|c|}{ Premenopausal } & \multicolumn{6}{|c|}{ Postmenopausal } \\
\hline & \multicolumn{2}{|c|}{ Whole body } & \multicolumn{2}{|c|}{ Lumbar } & \multicolumn{2}{|c|}{ Femoral neck } & \multicolumn{2}{|c|}{ Whole body } & \multicolumn{2}{|c|}{ Lumbar } & \multicolumn{2}{|c|}{ Femoral neck } \\
\hline & B & $p$ & B & $p$ & B & $p$ & B & $p$ & B & $p$ & B & $p$ \\
\hline \multicolumn{13}{|l|}{ Model 1} \\
\hline Calcium intake & 0.000018 & 0.592 & 0.000007 & 0.491 & 0.000004 & 0.696 & 0.000013 & 0.270 & 0.000031 & 0.064 & 0.000019 & 0.148 \\
\hline Phosphorus intake & 0.000010 & 0.149 & 0.000003 & 0.643 & 0.000001 & 0.882 & 0.000006 & 0.486 & 0.000014 & 0.371 & 0.000014 & 0.187 \\
\hline $\mathrm{Ca} / \mathrm{P}$ ratio & 0.008565 & 0.313 & 0.000873 & 0.922 & 0.001513 & 0.871 & 0.007024 & 0.412 & 0.010293 & 0.402 & -0.002908 & 0.751 \\
\hline \multicolumn{13}{|l|}{ Model 2} \\
\hline Calcium intake & 0.000020 & 0.029 & 0.000009 & 0.294 & 0.000006 & 0.501 & 0.000013 & 0.286 & 0.000031 & 0.052 & 0.000018 & 0.147 \\
\hline Phosphorus intake & 0.000011 & 0.097 & 0.000005 & 0.486 & 0.000001 & 0.777 & 0.000003 & 0.698 & 0.000008 & 0.583 & 0.000009 & 0.322 \\
\hline $\mathrm{Ca} / \mathrm{P}$ ratio & 0.009746 & 0.224 & 0.003217 & 0.701 & 0.003813 & 0.632 & 0.009180 & 0.298 & 0.013955 & 0.233 & 0.000190 & 0.982 \\
\hline \multicolumn{13}{|l|}{ Model 3} \\
\hline Calcium intake & 0.000022 & 0.022 & 0.000012 & 0.169 & 0.000005 & 0.564 & 0.000009 & 0.454 & 0.000025 & 0.112 & 0.000012 & 0.300 \\
\hline Phosphorus intake & 0.000012 & 0.072 & 0.000007 & 0.294 & 0.000002 & 0.725 & 0.000002 & 0.765 & 0.000007 & 0.608 & 0.000008 & 0.385 \\
\hline $\mathrm{Ca} / \mathrm{P}$ ratio & 0.008914 & 0.269 & 0.002167 & 0.798 & 0.001785 & 0.827 & 0.005130 & 0.596 & 0.006959 & 0.549 & -0.005030 & 0.534 \\
\hline
\end{tabular}

Model 1: adjustment for age, household income, education level, residential areas, alcohol consumption, smoking, physical activity, energy intake per day, dietary supplement, and duration of breast feeding. Model 2: adjustment for model 1 + body mass index. Model 3: adjustment for model $2+$ alkaline phosphatase, ferritin, and 25-hydroxyvitamin D. Ca/P ratio Calcium/phosphorus intake ratio. Results in bold indicate statistical significance at the 0.05 level. 
collected via a $24 \mathrm{~h}$ dietary recall by the participants, which could have resulted in a recall bias. A 1-day 24-h recall could not be enough to estimate the typical daily intake of an individual due to the day-to-day variability in food and nutrient intakes [53]. Third, we did not consider other nutritional factors such as dietary sodium or vitamin $\mathrm{K}$ that might affect bone health or mass, since the factors were not measured in the KNHANES. However, the strengths of this study were that the data were collected using a representative nationwide survey of the South Korean population and that this is the first study of Korean adults to investigate gender- and age-specific associations between dietary calcium and phosphorus intakes, and dietary calcium/phosphorus ratio and bone mass.

In conclusion, dietary calcium intake and calcium/ phosphorus ratio in men older than 50 years of age, and dietary calcium intake in premenopausal women had small but significant positive associations with bone mass in femoral neck or whole body. These findings suggest that increased calcium intake and high calcium/ phosphorus intake ratio might have beneficial effects on bone mass in Korean population. Further gender-and age-specific studies are needed to further identify the influence of calcium and phosphorus intakes, and the dietary calcium/phosphorus ratio on bone mass, and to evaluate the adequate amounts of dietary calcium and phosphorus intakes on bone health.

\section{Abbreviations}

BMD: Bone mineral density; BMl: Body mass index; DXA: Dual-energy X-ray absorptiometry; KCDC: The Korea Centers for Disease Control and Prevention; KNHANES: Korean National Health and Nutrition Examination Survey; MET: Metabolic equivalent of task.

\section{Competing interests}

The authors declare that they have no competing interests.

\section{Authors' contributions}

KJ, KSK, and SWS conceived the study. KSK, HNK, and SWS collected, analyzed and interpreted the data. KJL and SWS wrote the manuscript. KSK, HNK, and JAS supervised writing of the paper and provided critical revisions. All authors read and approved the final manuscript.

\section{Authors' information}

KLL: M.D., Department of Family Medicine, St. Vincent's Hospital, College of Medicine, The Catholic University of Korea.

KSK: M.D., Ph.D., Professor, Department of Family medicine, Seoul St. Mary's Hospital, College of Medicine, The Catholic University of Korea. HNK: M.D., MSc., Clinical assistant professor, Department of Family Medicine, St. Vincent's Hospital, College of Medicine, The Catholic University of Korea. JAS: M.D., Department of Family Medicine, St. Vincent's Hospital, College of Medicine, The Catholic University of Korea.

SWS: M.D., Ph.D., Professor, Department of Family Medicine, St. Vincent's Hospital, College of Medicine, The Catholic University of Korea.

\section{Author details}

${ }^{1}$ Department of Family Medicine, St. Vincent's Hospital, College of Medicine, The Catholic University of Korea, 93 Jungbudaero, Paldal-gu, Suwon, Gyeonggi-do 442-723, Republic of Korea. ${ }^{2}$ Department of Family medicine, Seoul St. Mary's Hospital, College of Medicine, The Catholic University of Korea, Seoul, South Korea.
Received: 2 September 2014 Accepted: 9 December 2014

Published: 13 December 2014

\section{References}

1. Peck WA, Burckhardt P, Christiansen C, Fleisch HA, Genant HK, Gennari C, Martin TJ, Martini L, Morita R, Ogata E, Rapado A, Shulman LE, Stern PH, Young RTT: Consensus development conference: diagnosis, prophylaxis, and treatment of osteoporosis. Am J Med 1993, 94:646-650.

2. Burge $R$, Dawson-Hughes B, Solomon DH, Wong JB, King A, Tosteson A: Incidence and economic burden of osteoporosis-related fractures in the United States, 2005-2025. J Bone Miner Res 2007, 22:465-475.

3. Hernlund E, Svedbom A, Ivergard M, Compston J, Cooper C, Stenmark J, McCloskey EV, Jonsson B, Kanis JA: Osteoporosis in the European Union: medical management, epidemiology and economic burden. A report prepared in collaboration with the International Osteoporosis Foundation (IOF) and the European Federation of Pharmaceutical Industry Associations (EFPIA). Arch Osteoporos 2013, 8:136.

4. Mithal A, Bansal B, Kyer CS, Ebeling P: The Asia-pacific regional audit-epidemiology, costs, and burden of osteoporosis in India 2013: a report of international osteoporosis foundation. Indian J Endocrinol Metab 2014, 18:449-454.

5. Wright NC, Looker AC, Saag KG, Curtis JR, Delzell ES, Randall S, Dawson-Hughes B: The recent prevalence of osteoporosis and low bone mass in the united states based on bone mineral density at the femoral neck or lumbar spine. J Bone Miner Res 2014, 29:2520-2526.

6. Cummings SR, Melton LJ: Epidemiology and outcomes of osteoporotic fractures. Lancet 2002, 359:1761-1767.

7. Cooper C, Campion G, Melton $\sqcup$ 3rd: Hip fractures in the elderly: a world-wide projection. Osteoporos Int 1992, 2:285-289.

8. Korean Centers for Disease Control and Prevention: Korea Health Statistics 2009: Korea National Health and Nutrition Examination Survey (KNHANES N-3); [https://knhanes.cdc.go.kr/knhanes/index.do]

9. Cree M, Soskolne CL, Belseck E, Hornig J, McElhaney JE, Brant R, Suarez-Almazor M: Mortality and institutionalization following hip fracture. J Am Geriatr Soc 2000, 48:283-288.

10. Mora S, Gilsanz V: Establishment of peak bone mass. Endocrinol Metab Clin North Am 2003, 32:39-63.

11. Lane NE: Epidemiology, etiology, and diagnosis of osteoporosis. Am J Obstet Gynecol 2006, 194:S3-S11.

12. Tanumihardjo SA: Vitamin A and bone health: the balancing act. J Clin Densitom 2013, 16:414-419.

13. Ahmadieh $H$, Arabi A: Vitamins and bone health: beyond calcium and vitamin D. Nutr Rev 2011, 69:584-598,

14. Iwamoto J: Vitamin K(2) therapy for postmenopausal osteoporosis. Nutrients 2014, 6:1971-1980.

15. Guralp O, Erel CT: Effects of vitamin K in postmenopausal women: mini review. Maturitas 2014, 77:294-299.

16. Park SM, Jee J, Joung JY, Cho YY, Sohn SY, Jin SM, Hur KY, Kim JH, Kim SW Chung JH, Lee MK, Min YK: High dietary sodium intake assessed by 24-hour urine specimen increase urinary calcium excretion and bone resorption marker. J Bone Metab 2014, 21:189-194.

17. Nieves JW: Bone. Maximizing bone health-magnesium, BMD and fractures. Nat Rev Endocrinol 2014, 10:255-256.

18. Orchard TS, Larson JC, Alghothani N, Bout-Tabaku S, Cauley JA, Chen Z, LaCroix AZ, Wactawski-Wende J, Jackson RD: Magnesium intake, bone mineral density, and fractures: results from the Women's Health Initiative Observational Study. Am J Clin Nutr 2014, 99:926-933.

19. Aggarwal $S$, Nityanand: Calcium and vitamin $D$ in post menopausal women. Indian J Endocrinol Metab 2013, 17:S618-S620.

20. Candido FG, Bressan J: Vitamin D: link between osteoporosis, obesity, and diabetes? Int J Mol Sci 2014, 15:6569-6591.

21. Calvo MS, Tucker KL: Is phosphorus intake that exceeds dietary requirements a risk factor in bone health? Ann N Y Acad Sci 2013, 1301:29-35

22. Pinheiro MM, Schuch NJ, Genaro PS, Ciconelli RM, Ferraz MB, Martini LA: Nutrient intakes related to osteoporotic fractures in men and women-the Brazilian Osteoporosis Study (BRAZOS). Nutr J 2009, 8:6.

23. Macdonald HM, New SA, Golden MH, Campbell MK, Reid DM: Nutritional associations with bone loss during the menopausal transition: evidence of a beneficial effect of calcium, alcohol, and fruit and vegetable 
nutrients and of a detrimental effect of fatty acids. Am J Clin Nutr 2004, 79:155-165.

24. Hooshmand S, Chai SC, Saadat RL, Payton ME, Brummel-Smith K, Arjmandi BH: Comparative effects of dried plum and dried apple on bone in postmenopausal women. Br J Nutr 2011, 106:923-930.

25. Rizzoli R: Dairy products, yogurts, and bone health. Am J Clin Nutr 2014, 99:1256s-1262s.

26. Garcia-Martinez O, Rivas A, Ramos-Torrecillas J, De Luna-Bertos E, Ruiz C: The effect of olive oil on osteoporosis prevention. Int J Food Sci Nutr 2014, 65:834-840.

27. Boskey AL: Mineralization, structure, and function of bone. In Dynamics of Bone and Cartilage Metabolism: Principles and Clinical Applications. 2nd edition. Edited by Seibel MJ, Robins SP, Bilezikian JP. San Diego: Academic Press; 2006:201-209.

28. Ito S, Ishida H, Uenishi K, Murakami K, Sasaki S: The relationship between habitual dietary phosphorus and calcium intake, and bone mineral density in young Japanese women: a cross-sectional study. Asia Pac J Clin Nutr 2011, 20:411-417.

29. Metz JA, Anderson JJ, Gallagher PN Jr: Intakes of calcium, phosphorus, and protein, and physical-activity level are related to radial bone mass in young adult women. Am J Clin Nutr 1993, 58:537-542.

30. Brot C, Jorgensen N, Madsen OR, Jensen LB, Sorensen OH: Relationships between bone mineral density, serum vitamin $D$ metabolites and calcium:phosphorus intake in healthy perimenopausal women. $J$ Intern Med 1999, 245:509-516.

31. Lewiecki EM, Gordon CM, Baim S, Leonard MB, Bishop NJ, Bianchi ML, Kalkwarf $\mathrm{HJ}$, Langman CB, Plotkin $\mathrm{H}$, Rauch F, Zemel BS, Binkley N, Bilezikian JP, Kendler DL, Hans DB, Silverman S: International society for clinical densitometry 2007 adult and pediatric official positions. Bone 2008, 43:1115-1121

32. Mu M, Wang SF, Sheng J, Zhao Y, Wang GX, Liu KY, Hu CL, Tao FB, Wang HL: Dietary patterns are associated with body mass index and bone mineral density in Chinese freshmen. J Am Coll Nutr 2014, 33:120-128.

33. Huttunen MM, Pietila PE, Viljakainen HT, Lamberg-Allardt CJ: Prolonged increase in dietary phosphate intake alters bone mineralization in adult male rats. J Nutr Biochem 2006, 17:479-484

34. Katsumata S, Masuyama R, Uehara M, Suzuki K: High-phosphorus diet stimulates receptor activator of nuclear factor-kappaB ligand mRNA expression by increasing parathyroid hormone secretion in rats. Br J Nutr 2005, 94:666-674.

35. Kemi VE, Karkkainen MU, Lamberg-Allardt CJ: High phosphorus intakes acutely and negatively affect $\mathrm{Ca}$ and bone metabolism in a dose-dependent manner in healthy young females. Br J Nutr 2006, 96:545-552.

36. Takeda E, Yamamoto H, Yamanaka-Okumura H, Taketani Y: Dietary phosphorus in bone health and quality of life. Nutr Rev 2012, 70:311-321.

37. Vicente-Rodriguez G, Ezquerra J, Mesana MI, Fernandez-Alvira JM, Rey-Lopez JP, Casajus JA, Moreno LA: Independent and combined effect of nutrition and exercise on bone mass development. J Bone Miner Metab 2008, 26:416-424.

38. Calvo MS: The effects of high phosphorus intake on calcium homeostasis. Adv Nutr Res 1994, 9:183-207.

39. Takeda E, Yamamoto H, Yamanaka-Okumura H, Taketani Y: Increasing dietary phosphorus intake from food additives: potential for negative impact on bone health. Adv Nutr 2014, 5:92-97.

40. Nordin BC: Calcium requirement is a sliding scale. Am J Clin Nutr 2000, 71:1381-1383

41. Calvo MS: Dietary phosphorus, calcium metabolism and bone. J Nutr 1993, 123:1627-1633.

42. Fernando GR, Martha RM, Evangelina R: Consumption of soft drinks with phosphoric acid as a risk factor for the development of hypocalcemia in postmenopausal women. J Clin Epidemiol 1999, 52:1007-1010.

43. Lombardi-Boccia G, Aguzzi A, Cappelloni M, Di Lullo G, Lucarini M: Total-diet study: dietary intakes of macro elements and trace elements in Italy. Br J Nutr 2003, 90:1117-1121.

44. Salamoun MM, Kizirian AS, Tannous Rl, Nabulsi MM, Choucair MK, Deeb ME, El-Hajj Fuleihan GA: Low calcium and vitamin D intake in healthy children and adolescents and their correlates. Eur J Clin Nutr 2005, 59:177-184.

45. Calvo MS, Park YK: Changing phosphorus content of the U.S. diet: potential for adverse effects on bone. J Nutr 1996, 126:1168s-1180s.

46. Takeda E, Sakamoto K, Yokota K, Shinohara M, Taketani Y, Morita K, Yamamoto H, Miyamoto K, Shibayama M: Phosphorus supply per capita from food in Japan between 1960 and 1995. J Nutr Sci Vitaminol (Tokyo) 2002, 48:102-108.

47. Kemi VE, Karkkainen MU, Rita HJ, Laaksonen MM, Outila TA, Lamberg-Allardt CJ: Low calcium:phosphorus ratio in habitual diets affects serum parathyroid hormone concentration and calcium metabolism in healthy women with adequate calcium intake. Br J Nutr 2010, 103:561-568.

48. Calvo MS, Kumar R, Heath $H$ 3rd: Elevated secretion and action of serum parathyroid hormone in young adults consuming high phosphorus, low calcium diets assembled from common foods. I Clin Endocrinol Metab 1988, 66:823-829.

49. Smerdely P, Seller M, Smith A, Day P, Diamond T: Predictors of bone mass in healthy older men in the community. Med J Aust 2000, 173:183-186.

50. Whiting SJ, Boyle JL, Thompson A, Mirwald RL, Faulkner RA: Dietary protein, phosphorus and potassium are beneficial to bone mineral density in adult men consuming adequate dietary calcium. J Am Coll Nutr 2002, 21:402-409.

51. Garton M, Martin J, New S, Lee S, Loveridge N, Milne J, Reid D, Reid I, Robins $S$ : Bone mass and metabolism in women aged 45-55. Clin Endocrinol (Oxf) 1996, 44:563-570.

52. Prince RL, Dick I, Devine A, Price Rl, Gutteridge DH, Kerr D, Criddle A, Garcia-Webb P, St John A: The effects of menopause and age on calcitropic hormones: a cross-sectional study of 655 healthy women aged 35 to 90 J Bone Miner Res 1995, 10:835-842.

53. Illner AK, Freisling H, Boeing H, Huybrechts I, Crispim SP, Slimani N: Review and evaluation of innovative technologies for measuring diet in nutritional epidemiology. Int J Epidemiol 2012, 41:1187-1203.

doi:10.1186/1475-2891-13-114

Cite this article as: Lee et al: Association between dietary calcium and phosphorus intakes, dietary calcium/phosphorus ratio and bone mass in the Korean population. Nutrition Journal 2014 13:114.

\section{Submit your next manuscript to BioMed Central and take full advantage of:}

- Convenient online submission

- Thorough peer review

- No space constraints or color figure charges

- Immediate publication on acceptance

- Inclusion in PubMed, CAS, Scopus and Google Scholar

- Research which is freely available for redistribution 